\title{
Characterization of Fatty Acid Profile of Argan Oil and Other Edible Vegetable Oils by Gas Chromatography and Discriminant Analysis
}

\author{
Ascensión Rueda, ${ }^{1}$ Isabel Seiquer, ${ }^{2}$ Manuel Olalla, ${ }^{1}$ Rafael Giménez, \\ Luis Lara, ${ }^{2}$ and Carmen Cabrera-Vique ${ }^{1}$ \\ ${ }^{1}$ Departamento de Nutrición y Bromatología, Facultad de Farmacia, Universidad de Granada, Campus de Cartuja, \\ 18071 Granada, Spain \\ ${ }^{2}$ Departamento de Fisiología y Bioquímica de la Nutrición Animal, Estación Experimental del Zaidín (CSIC), \\ Camino del Jueves s/n, Armilla, 18100 Granada, Spain
}

Correspondence should be addressed to Isabel Seiquer; isabel.seiquer@eez.csic.es

Received 1 April 2014; Revised 4 July 2014; Accepted 24 July 2014; Published 18 August 2014

Academic Editor: M. Beatriz P. P. Oliveira

Copyright (c) 2014 Ascensión Rueda et al. This is an open access article distributed under the Creative Commons Attribution License, which permits unrestricted use, distribution, and reproduction in any medium, provided the original work is properly cited.

\begin{abstract}
Virgin argan oil is an emergent oil that is being introduced into specialized international markets as a healthy and luxury food. In order to compare the fatty acid composition of argan oil with that of the eleven other vegetable edible oils, a combination of gas chromatography as analytical technique and multivariate discriminant analysis was applied. This analysis takes into account the conjoint effect of all the variables analyzed in the discrimination between oils and also shows the contribution of each variable to oils characterization. The model correctly classified $100 \%$ oil samples. According to the fatty acid composition, argan oil showed closest similarity firstly with sesame oil and secondly with high oleic sunflower oil. Olive oil was close to avocado oil and almond oil, followed by argan oil. Thus, similarities and differences between vegetable oils based on their fatty acid profile were established by the application of multivariate discriminant analysis. This method was proven to be a useful tool to study the relationships between oils according to the fat composition and to determine the importance of the fatty acid variables on the oils classification.
\end{abstract}

\section{Introduction}

Virgin argan oil has been investigated due to its particular composition and potential health benefits $[1,2]$. This oil is mainly produced in Southwest of Morocco from the nut of the argan tree (Argania spinosa, L.) and represents an important fat source in the Magreb area [3]. However, nowadays its consumption has been extended to other countries, that is, USA or Japan. In 2003, Morocco introduced a new regulation to define quality specifications for virgin argan oil and to classify argan oils into different categories [4], being extra virgin argan oil the highest quality category. The traditional extraction method (hand pressure) coexists with the semiindustrial method (mechanical cold pressure without water addition) applied in recently developed cooperatives and that allows obtaining high-quality oils [2]. Recent studies suggest that argan oil may play a significant role in the prevention of cardiovascular diseases due to its antioxidant potential and its hypolipidemic, hypocholesterolemic, and antihypertensive effects $[5,6]$. According to bibliographic data, argan oil is rich in oleic and linoleic acids, polyphenols and tocopherols [79], and other minor compounds such as sterols, carotenoids, xanthophylls, squalene, coenzyme $\mathrm{Q}_{10}$, and melatonin $[2,3$, $10]$.

The scientific evidence has largely demonstrated that the "quality" of fat, apart from the "quantity" of fat, has a strong impact on consumer health. Public health institutes of different countries over the world, as well as international organisms such as the FAO/OMS, have established recommended daily intakes for each type of fatty acids (FA), that is, saturated (SFA), monounsaturated (MUFA), and polyunsaturated (PUFA), generally limiting the SFA 
intake and promoting MUFA and PUFA consumption [11]. Nowadays, oils rich in unsaturated fatty acids are largely recommended as substitutes of saturated-fats used in industrialized countries [11]. Thus, FA composition occupies a prominent place in evaluating the nutritional quality of oils. This concern for the FA impact has led nutritionists and food manufacturers to look for fats and oils containing specific FA of supposed beneficial effects, while researchers have directed their efforts to compare different oils according to their FA composition [12]. In this line, the nutritional qualities of argan oil have been proposed to be identical to those of olive oil, given that both contain high levels of oleic acid, with linoleic acid as the second major PUFA and being the SFA of both oils palmitic and stearic acids [1]. Thus, FA percentage distribution allows suggesting similarities and distinctiveness among oils. However, the relationships between oils are affected by all the variables and not only by majority FA [13]. Therefore, only using multivariate methods to analyze the combination effects of all variables, holistic information of samples can be obtained.

The aim of this work was to (1) fully characterize the FA profile of argan oil and eleven other vegetable oils, (2) apply multivariate discriminant analysis to study the relationship between oils according to their FA composition, and (3) determine which of the fatty acids accounts the most for the differences on the discrimination of vegetable oils. With this purpose, FA profile of the different oils was performed using gas chromatography.

\section{Materials and Methods}

2.1. Samples. A total of 14 samples of virgin argan oils, produced in Morocco by the semi-industrial method and commercialized in the Spanish market, were analysed. The other vegetable oils were almond, wheat germ, high oleic sunflower, linseed, walnut, avocado, sesame, grape seed, soybean, pumpkin seed, and virgin olive oil. Four samples of each type of oil were analysed; all of them were purchased from local supermarkets and specialised groceries. Only sunflower and grape seed oils were refined, whereas the remainders were virgin oils. All samples were maintained at temperature of $4^{\circ} \mathrm{C}$ in an inert nitrogen atmosphere until analysis.

2.2. Apparatus and Chemicals. Main fatty acids were quantified by gas chromatography using a Perkin Elmer Autosystem gas chromatograph (Perkin-Elmer, Norwalk, CT, USA), equipped with a flame ionization detector (FID) and conventional injector. A capillary column Supelco SPTM 2380 ( $30 \mathrm{~m} \times 0.25 \mathrm{~mm}$ i.d., $0.2 \mu \mathrm{m}$ film thickness) was used. All chemicals were of analytical grade or higher purity unless otherwise stated. The fatty acid standard mix FAME mix 47885-U provided by Sigma (Sigma-Aldrich, Milan, Italy) was used for FA identification, according to their retention times. Sodium methylate $0.2 \mathrm{~N}$, sulphuric acid, and n-hexane were purchased from Panreac (Panreac, Barcelona, Spain) and used to extract fatty acid methyl esters.
2.3. Fatty Acid Analysis. Analyses were carried out in triplicate. For determining the FA composition of oils, adaptation of the official method of the International Olive Oil Council [14], which precision has been statistically assessed by Cert et al. [15], was used. Fatty acids were determined as fatty acid methyl esters (FAME) after treatment of $0.3 \mathrm{~g}$ of the oil sample with $5 \mathrm{~mL}$ of sodium methylate $0.2 \mathrm{~N}$. FAME were prepared by acidic esterification in the presence of methanolic $\mathrm{H}_{2} \mathrm{SO}_{4}$ $(4 \%, v / v)$; the organic phase was removed with $n$-hexane $(5 \mathrm{~mL})$. The injection volume was $2 \mu \mathrm{L}$, and the carrier gas was nitrogen $(15 \mathrm{psi})$. The oven temperature was kept at $60^{\circ} \mathrm{C}$ for $3 \mathrm{~min}$ and was raised to $170^{\circ} \mathrm{C}$ at a rate of $5^{\circ} \mathrm{C} / \mathrm{min}$; after $9 \mathrm{~min}$ the temperature was raised at $250^{\circ} \mathrm{C}$ at a rate of $10^{\circ} \mathrm{C} / \mathrm{min}$. The injector and detector were maintained at $230^{\circ} \mathrm{C}$ and $250^{\circ} \mathrm{C}$, respectively. Individual FAME were identified by comparing their retention times with those of pure standards. Quantification of individual fatty acids was carried out by calculating the corresponding relative percentage of the total FAME, according to the area normalization procedure. In addition, sums of total SFA, MUFA, PUFA, PUFA n-3 and $n-6$, and SFA/PUFA and n-6/n-3 ratios have been calculated.

2.4. Statistical Analysis. Results of individual FA content and sums of FA of the different oils were analyzed by oneway ANOVA followed by Tuckey test to compare significant variations between means $(P<0.05)$. Moreover, in order to verify the capacity of the FA analysis as a tool for oils characterization a multivariate discriminant analysis was performed. The basic purpose of discriminant analysis is to estimate the relationship between a single categorical dependent variable (the type of oil in this case) and a set of quantitative independent variables (the percentage contents of the fatty acids), since the relationships between oils are affected by all the variables and only analyzing the combination effects by multivariate methods similarities and differences between oils can be established effectively. This analysis can determine which of the independent variables accounts the most for the differences in the average score profiles of the different oils. Moreover, graph representation of this analysis allows assessing the similarity of the oils by their FA composition. All the statistical analyses were carried out using the StatGraphics Centurion XV software (StatPoint Technologies, Inc., USA, 2006).

\section{Results and Discussion}

3.1. Fatty Acid Profile in Virgin Argan Oil. The fatty acid composition and the related sums and ratios of the 14 samples of virgin argan oil analyzed are summarized in Tables 1 and 2 , respectively. Figure 1 shows a chromatogram of a sample of argan oil. Values of the FA analyzed in all the argan oil samples were within the limits established by the Moroccan norm for virgin argan oils [4] as follows (weight $\%$ of methyl esters): myristic acid $(\mathrm{C} 14: 0) \leq 0.2$, palmitic acid (C16:0) 11.5-15.0, palmitoleic acid $(\mathrm{C} 16: 1) \leq 0.2$, margaric acid $(\mathrm{Cl7}: 0)$ traces, stearic acid (C18:0) 4.3-7.2, oleic acid (C18:1 n-9) 43.0-49.1, linoleic acid (C18:2 n-6) 29.3-36.0, arachidic acid (C20:0) $\leq$ 0.5 , gadoleic acid $(\mathrm{C} 20: 1 \mathrm{n}-11) \leq 0.5$, and behenic acid (C22:0) 


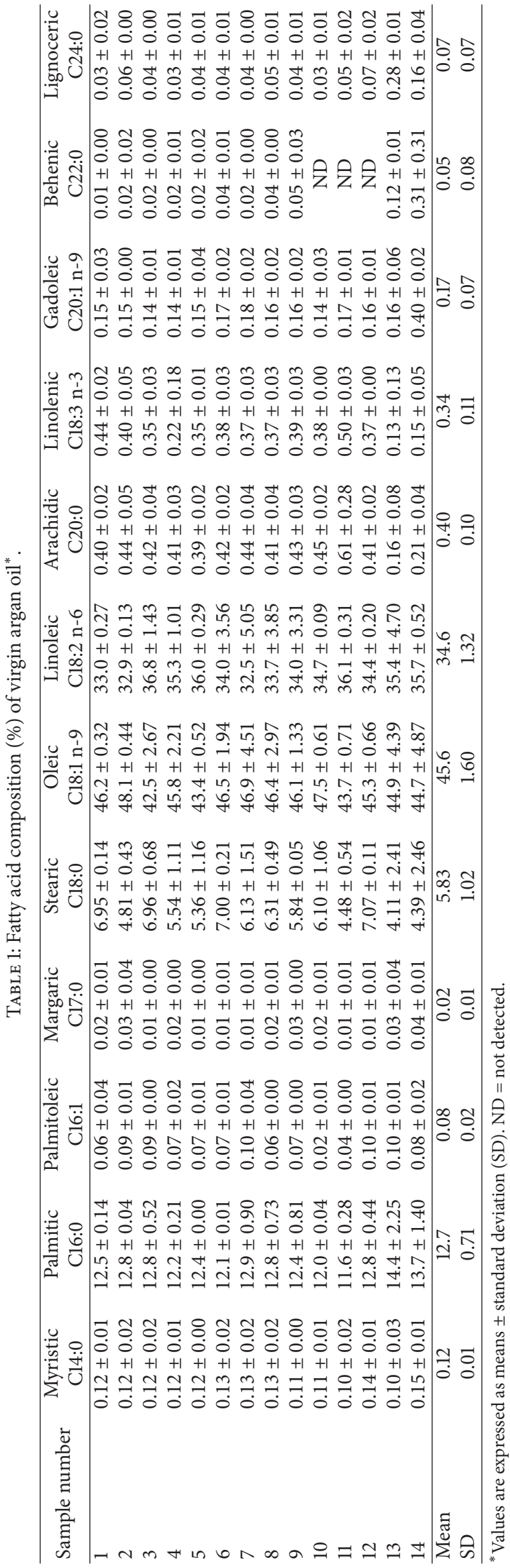


TABLE 2: Sum of fatty acids in virgin argan oil*.

\begin{tabular}{|c|c|c|c|c|c|c|c|}
\hline Sample number & $\Sigma$ SFA & $\Sigma$ MUFA & $\Sigma$ PUFA & $\Sigma$ PUFA n-3 & $\Sigma$ PUFA n-6 & SFA/PUFA & $n-6 / n-3$ ratio \\
\hline 1 & $20.1 \pm 0.02$ & $46.5 \pm 0.25$ & $33.5 \pm 0.40$ & $0.44 \pm 0.03$ & $33.0 \pm 0.06$ & 0.60 & 75.0 \\
\hline 2 & $18.2 \pm 0.52$ & $48.4 \pm 0.44$ & $33.3 \pm 0.08$ & $0.40 \pm 0.05$ & $32.9 \pm 0.13$ & 0.55 & 82.2 \\
\hline 3 & $20.1 \pm 1.19$ & $42.7 \pm 2.64$ & $37.1 \pm 1.45$ & $0.35 \pm 0.03$ & $36.8 \pm 1.42$ & 0.54 & 105 \\
\hline 4 & $18.3 \pm 1.35$ & $46.1 \pm 2.18$ & $35.6 \pm 0.83$ & $0.22 \pm 0.18$ & $35.4 \pm 1.01$ & 0.51 & 160 \\
\hline 5 & $20.0 \pm 0.25$ & $43.6 \pm 0.55$ & $36.4 \pm 0.30$ & $0.35 \pm 0.01$ & $36.0 \pm 0.29$ & 0.55 & 102 \\
\hline 6 & $18.8 \pm 1.58$ & $46.7 \pm 1.94$ & $34.4 \pm 3.52$ & $0.38 \pm 0.03$ & $34.0 \pm 3.55$ & 0.55 & 89.4 \\
\hline 7 & $19.2 \pm 0.45$ & $47.2 \pm 4.57$ & $32.9 \pm 5.02$ & $0.37 \pm 0.03$ & $32.5 \pm 5.04$ & 0.58 & 87.8 \\
\hline 8 & $19.3 \pm 0.83$ & $46.6 \pm 2.98$ & $34.1 \pm 3.81$ & $0.37 \pm 0.03$ & $33.7 \pm 3.84$ & 0.56 & 90.3 \\
\hline 9 & $19.2 \pm 1.94$ & $46.4 \pm 1.34$ & $34.4 \pm 3.28$ & $0.39 \pm 0.03$ & $34.0 \pm 3.30$ & 0.56 & 87.2 \\
\hline 10 & $17.1 \pm 0.54$ & $47.7 \pm 0.62$ & $35.1 \pm 0.09$ & $0.38 \pm 0.01$ & $34.8 \pm 0.08$ & 0.49 & 91.6 \\
\hline 11 & $19.5 \pm 0.45$ & $43.9 \pm 0.72$ & $36.6 \pm 0.27$ & $0.50 \pm 0.03$ & $36.1 \pm 0.31$ & 0.53 & 72.2 \\
\hline 12 & $19.6 \pm 0.85$ & $45.6 \pm 0.65$ & $34.8 \pm 0.18$ & $0.37 \pm 0.00$ & $34.4 \pm 0.19$ & 0.56 & 92.8 \\
\hline 13 & $19.2 \pm 0.24$ & $45.2 \pm 0.60$ & $35.5 \pm 4.56$ & $0.13 \pm 0.13$ & $35.4 \pm 4.69$ & 0.55 & 272 \\
\hline 14 & $18.9 \pm 1.35$ & $42.2 \pm 0.88$ & $35.9 \pm 0.46$ & $0.15 \pm 0.05$ & $35.7 \pm 0.51$ & 0.53 & 238 \\
\hline Mean & 19.2 & 45.8 & 34.9 & 0.34 & 34.6 & 0.55 & 117 \\
\hline SD & 0.84 & 1.60 & 1.29 & 0.11 & 1.32 & 0.03 & 63.0 \\
\hline
\end{tabular}

${ }^{*}$ Values are expressed as means \pm standard deviation $(\mathrm{SD}) . \Sigma \mathrm{SFA}=$ sum of myristic, palmitic, margaric, stearic, arachidic, behenic, and lignoceric acids; $\Sigma \mathrm{MUFA}$ $=$ sum of palmitoleic, oleic, and gadoleic acids; $\Sigma$ PUFA = sum of linoleic and linolenic acids; $\Sigma$ PUFA $n-3=$ linolenic acid; $\Sigma$ PUFA $n-6=$ linoleic acid.

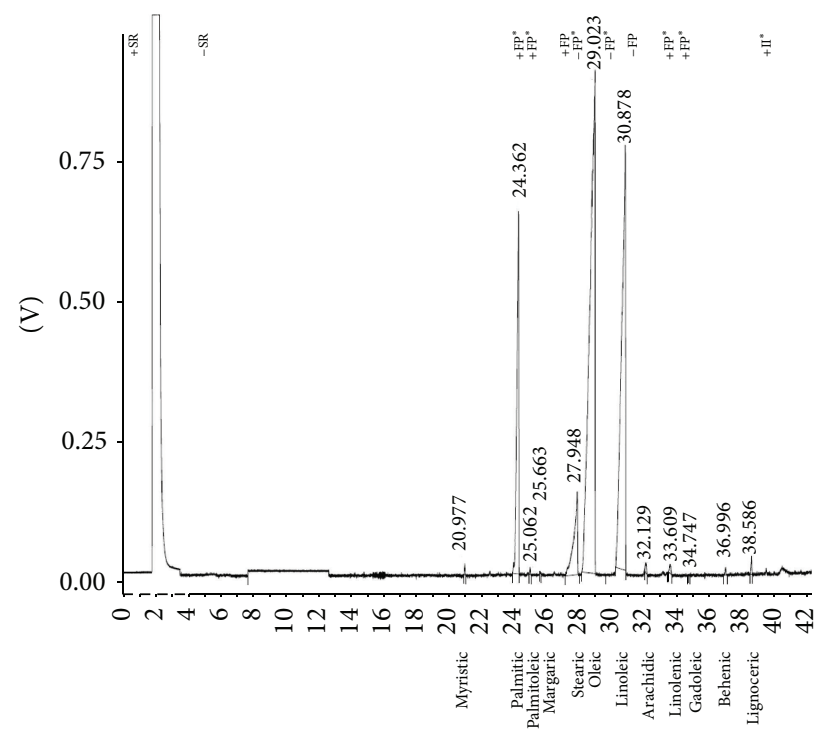

FIGURE 1: Chromatogram of FAME of a sample of argan oil.

$\leq$ 0.2. The only exception was $\alpha$-linolenic acid (C18:3 n-3), since slightly higher values than that established $(\leq 0.3)$ were found for 11 samples.

Total unsaturated FA (MUFA + PUFA) in virgin argan oils composed $80 \%$ of the total FA, in accordance with previous bibliographic data $[2,8,16,17]$. These fractions corresponded, almost entirely, to oleic and linoleic acids, respectively (average values of $45.6 \%$ of oleic acid and $34.6 \%$ of linoleic acid). Palmitic acid and stearic acid (12.7 and $5.83 \%$ on average, resp.) represented the greatest proportion of SFA in argan oil. In previous studies by our research group including samples of virgin argan oil of very different quality (extra virgin, fine virgin, ordinary virgin, and lampant) showed oleic acid contents ranging from 36.50 to $47.70 \%$ [18].

The clinical relevance and the nutritional value of oleic acid have been extensively described and it is known to have hypocholesterolemic and hypotensive effects [1]. Moreover, argan oil promotes a proper supply of n- 6 PUFA, mainly represented by the linoleic acid, precursor of the n- 6 series with important pharmacological properties and protective effects against degenerative diseases, such as cardiovascular disease and cancer [19]. It is estimated that 17 to $21 \mathrm{~g}$ of argan oil are sufficient to meet the daily needs of linoleic acid [20]. However, only small quantities of n-3 PUFA are provided by argan oil (content up to $0.50 \%$ of $\alpha$-linolenic acid has been found in argan oils from the present assay) and therefore argan oil feeding should be supplemented by an extra supply of n-3 FA. Hilali et al. [8] reported proportions of $0.030-0.10 \%$ of $\alpha$-linolenic acid and Harhar et al. [21] of $0.10-0.20 \%$. Due to the poor linolenic acid content, the $\mathrm{n}$ $6 / n-3$ ratio of virgin argan oil is very high. Because of its FA composition and the elevated presence of minor compounds such as $\gamma$-tocopherol, several studies have confirmed the antiatherogenic and hypotensive effects of the argan oil, which can be used for reducing cardiovascular risks [5].

3.2. Fatty Acid Profile in Other Vegetable Edible Oils. Fatty acid composition and the related sums and ratios of the other oils analyzed in the present study are presented in Tables 3 and 4, respectively. Dubois et al. [12] classified vegetable oils according to their FA profiles into different classes and subclasses. Following this classification, four oils of our study may be included in the MUFA class: almond, avocado, extra virgin olive oil, and argan oil. Within this group, the first three belong to the MUFA subclass ( $>60 \%$ ), specially rich in oleic acid, with contents ranging from $60.6 \%$ (avocado) to 
TABLE 3: Fatty acid composition (\%) in edible vegetable oils*.

\begin{tabular}{|c|c|c|c|c|c|c|c|c|c|c|c|c|}
\hline & Myristic & Palmitic & Palmitoleic & Margaric & Stearic & Oleic & Linoleic & Arachidic & Linolenic & Gadoleic & Behenic & Lignoceric \\
\hline & C14:0 & C16:0 & C16:1 & C17:0 & C18:0 & C18:1 n-9 & $C 18: 2 n-6$ & C20:0 & $C 18: 3 n-3$ & C20:1 n-9 & C22:0 & C24:0 \\
\hline Almond oil & $0.02^{\mathrm{a}}$ & $6.73^{\mathrm{ab}}$ & $0.48^{\mathrm{a}}$ & $0.05^{\mathrm{ab}}$ & $1.78^{\mathrm{ab}}$ & $66.69^{\mathrm{ef}}$ & $23.9^{\mathrm{b}}$ & $0.11^{\mathrm{ab}}$ & $0.14^{\mathrm{a}}$ & ND & 0.07 & $0.03^{\mathrm{a}}$ \\
\hline $\begin{array}{l}\text { Wheat germ } \\
\text { oil }\end{array}$ & $0.12^{\mathrm{ab}}$ & $21.1^{\mathrm{e}}$ & $0.12^{\mathrm{a}}$ & $0.09^{\mathrm{ab}}$ & $2.79^{\mathrm{abc}}$ & $15.84^{\mathrm{a}}$ & $53.0^{\mathrm{d}}$ & $1.73^{\mathrm{e}}$ & $4.68^{\mathrm{b}}$ & $0.24^{\mathrm{ab}}$ & 0.04 & $0.20^{\mathrm{ab}}$ \\
\hline Sunflower oil & $0.05^{\mathrm{ab}}$ & $4.98^{\mathrm{a}}$ & $0.10^{\mathrm{a}}$ & $0.04^{\mathrm{ab}}$ & $3.24^{\mathrm{abc}}$ & $53.11^{\mathrm{d}}$ & $37.8^{\mathrm{c}}$ & $0.10^{\mathrm{ab}}$ & $0.28^{\mathrm{a}}$ & $0.04^{\mathrm{a}}$ & 0.03 & $0.22^{\mathrm{ab}}$ \\
\hline Linseed oil & ND & $5.88^{\mathrm{ab}}$ & $0.03^{\mathrm{a}}$ & $0.02^{\mathrm{a}}$ & $3.10^{\mathrm{abc}}$ & $20.50^{\mathrm{ab}}$ & $15.0^{\mathrm{ab}}$ & $0.06^{\mathrm{ab}}$ & $55.2^{\mathrm{d}}$ & $0.04^{\mathrm{a}}$ & 0.05 & $0.10^{\mathrm{a}}$ \\
\hline Walnut oil & $0.13^{b c}$ & $8.02^{\mathrm{ab}}$ & $0.23^{\mathrm{a}}$ & $0.18^{\mathrm{ab}}$ & $4.64^{\text {cd }}$ & $26.31^{\mathrm{b}}$ & $60.4^{\mathrm{de}}$ & $0.02^{\mathrm{a}}$ & $0.05^{\mathrm{a}}$ & $0.04^{\mathrm{a}}$ & 0.03 & $0.01^{\mathrm{a}}$ \\
\hline Avocado oil & $0.14^{\mathrm{bc}}$ & $16.3^{\mathrm{d}}$ & $4.59^{\mathrm{b}}$ & $0.34^{\mathrm{b}}$ & $1.50^{\mathrm{a}}$ & $60.61^{\mathrm{de}}$ & $14.7^{\mathrm{ab}}$ & $0.36^{\mathrm{abcd}}$ & $0.73^{\mathrm{a}}$ & $0.09^{\mathrm{a}}$ & 0.11 & $0.50^{\mathrm{b}}$ \\
\hline Sesame oil & $\mathrm{ND}$ & $9.82^{b c}$ & $0.11^{\mathrm{a}}$ & $0.02^{\mathrm{a}}$ & $5.96^{\mathrm{d}}$ & $41.12^{c}$ & $41.8^{\mathrm{c}}$ & $0.30^{\mathrm{abcd}}$ & $0.51^{a}$ & $0.12^{\mathrm{a}}$ & 0.10 & $0.18^{\mathrm{ab}}$ \\
\hline $\begin{array}{l}\text { Grape seed } \\
\text { oil }\end{array}$ & $0.05^{\mathrm{ab}}$ & $7.66^{\mathrm{ab}}$ & $0.03^{\mathrm{a}}$ & $0.11^{\mathrm{ab}}$ & $4.53^{\mathrm{cd}}$ & $17.65^{\mathrm{ab}}$ & $69.3^{\mathrm{e}}$ & $0.16^{\mathrm{abc}}$ & $0.33^{\mathrm{a}}$ & $0.02^{\mathrm{a}}$ & 0.04 & $0.13^{\mathrm{a}}$ \\
\hline Soybean oil & $0.06^{\mathrm{ab}}$ & $9.17^{\mathrm{abc}}$ & $0.08^{\mathrm{a}}$ & $0.08^{\mathrm{ab}}$ & $3.81^{\mathrm{bc}}$ & $24.44^{\mathrm{ab}}$ & $54.0^{\mathrm{d}}$ & $0.05^{\mathrm{a}}$ & $8.03^{\mathrm{c}}$ & ND & 0.05 & $0.24^{\mathrm{ab}}$ \\
\hline Pumpkin oil & $0.22^{c}$ & $15.6^{\mathrm{d}}$ & $0.15^{\mathrm{a}}$ & $\mathrm{ND}$ & $3.38^{\mathrm{abc}}$ & $24.52^{\mathrm{ab}}$ & $54.7^{\mathrm{d}}$ & $0.64^{\mathrm{d}}$ & $0.43^{\mathrm{a}}$ & ND & 0.17 & $0.16^{\mathrm{ab}}$ \\
\hline Olive oil & ND & $13.6^{\mathrm{cd}}$ & $0.50^{\mathrm{a}}$ & $\mathrm{ND}$ & $3.28^{\mathrm{abc}}$ & $75.40^{\mathrm{f}}$ & $5.50^{\mathrm{a}}$ & $0.55^{\mathrm{cd}}$ & $0.78^{\mathrm{a}}$ & $0.42^{\mathrm{b}}$ & ND & $0.03^{\mathrm{a}}$ \\
\hline Argan oil & $0.12^{\mathrm{b}}$ & $12.7^{\mathrm{cd}}$ & $0.08^{\mathrm{a}}$ & $0.02^{\mathrm{a}}$ & $5.83^{\mathrm{d}}$ & $45.59^{\mathrm{c}}$ & $34.6^{\mathrm{c}}$ & $0.40^{\text {bcd }}$ & $0.35^{\mathrm{a}}$ & $0.17^{\mathrm{a}}$ & 0.05 & $0.07^{\mathrm{a}}$ \\
\hline SEM & 0.0064 & 0.2575 & 0.0298 & 0.0173 & 0.1153 & 0.5024 & 0.5200 & 0.0233 & 0.1665 & 0.0152 & 0.0084 & 0.0183 \\
\hline$P$ value & $<0.0001$ & $<0.0001$ & $<0.0001$ & 0.0070 & $<0.0001$ & $<0.0001$ & $<0.0001$ & $<0.0001$ & $<0.0001$ & $<0.0001$ & NS & $<0.001$ \\
\hline
\end{tabular}

${ }^{*}$ Values are expressed as means \pm SEM

a,b,c,d,e,f Different superscripts indicate significant differences between oils (one-way ANOVA followed by Tuckey test, $P<0.05$ ).

ND: not detected. NS: not significant $(P>0.05)$.

TABLE 4: Sum of fatty acids in edible vegetable oils* .

\begin{tabular}{|c|c|c|c|c|c|c|c|}
\hline & $\Sigma$ SFA & $\Sigma$ MUFA & $\Sigma$ PUFA & $\Sigma$ PUFA n-3 & $\Sigma$ PUFA n-6 & SFA/PUFA & n-6/n-3 ratio \\
\hline Almond oil & $8.79^{\mathrm{a}}$ & $67.1^{\mathrm{ef}}$ & $24.0^{\mathrm{b}}$ & $0.14^{\mathrm{a}}$ & $23.9^{\mathrm{b}}$ & $0.37^{\mathrm{ab}}$ & $171^{\mathrm{ab}}$ \\
\hline Wheat germ oil & $26.1^{\mathrm{e}}$ & $16.2^{\mathrm{a}}$ & $57.7^{\mathrm{d}}$ & $4.68^{\mathrm{b}}$ & $53.0^{\mathrm{d}}$ & $0.48^{\mathrm{ab}}$ & $11.3^{\mathrm{a}}$ \\
\hline Sunflower oil & $8.65^{\mathrm{a}}$ & $53.2^{\mathrm{d}}$ & $38.1^{\mathrm{c}}$ & $0.28^{\mathrm{a}}$ & $37.8^{\mathrm{c}}$ & $0.23^{\mathrm{ab}}$ & $135^{\mathrm{ab}}$ \\
\hline Linseed oil & $9.20^{\mathrm{a}}$ & $20.6^{\mathrm{ab}}$ & $70.2^{\mathrm{e}}$ & $55.2^{\mathrm{d}}$ & $15.0^{\mathrm{ab}}$ & $0.13^{\mathrm{a}}$ & $0.27^{\mathrm{a}}$ \\
\hline Walnut oil & $13.3^{\mathrm{ab}}$ & $26.6^{\mathrm{b}}$ & $60.4^{\mathrm{de}}$ & $0.05^{\mathrm{a}}$ & $60.4^{\mathrm{de}}$ & $0.22^{\mathrm{ab}}$ & $1208^{c}$ \\
\hline Avocado oil & $19.2^{\mathrm{cd}}$ & $65.3^{\mathrm{e}}$ & $15.5^{\mathrm{ab}}$ & $0.73^{\mathrm{a}}$ & $14.7^{\mathrm{ab}}$ & $1.40^{\mathrm{c}}$ & $20.1^{\mathrm{a}}$ \\
\hline Sesame oil & $16.4^{\mathrm{bcd}}$ & $41.4^{\mathrm{c}}$ & $42.3^{\mathrm{c}}$ & $0.51^{\mathrm{a}}$ & $41.8^{\mathrm{c}}$ & $0.39^{\mathrm{ab}}$ & $81.9^{\mathrm{ab}}$ \\
\hline Grape seed oil & $12.7^{\mathrm{ab}}$ & $17.7^{\mathrm{ab}}$ & $69.6^{\mathrm{e}}$ & $0.33^{\mathrm{a}}$ & $69.3^{\mathrm{e}}$ & $0.18^{\mathrm{ab}}$ & $210^{\mathrm{b}}$ \\
\hline Soybean oil & $13.5^{\mathrm{abc}}$ & $24.5^{\mathrm{ab}}$ & $62.0^{\mathrm{de}}$ & $8.03^{\mathrm{c}}$ & $54.0^{\mathrm{d}}$ & $0.22^{\mathrm{ab}}$ & $6.72^{\mathrm{a}}$ \\
\hline Pumpkin oil & $20.2^{\mathrm{d}}$ & $24.7^{\mathrm{ab}}$ & $55.1^{\mathrm{d}}$ & $0.43^{\mathrm{a}}$ & $54.7^{\mathrm{d}}$ & $0.37^{\mathrm{ab}}$ & $127^{\mathrm{ab}}$ \\
\hline Olive oil & $17.5^{\mathrm{bcd}}$ & $76.3^{\mathrm{f}}$ & $6.28^{\mathrm{a}}$ & $0.78^{\mathrm{a}}$ & $5.50^{\mathrm{a}}$ & $2.79^{\mathrm{d}}$ & $7.05^{\mathrm{a}}$ \\
\hline Argan oil & $19.2^{\mathrm{d}}$ & $45.8^{\mathrm{cd}}$ & $35.0^{\mathrm{c}}$ & $0.35^{\mathrm{a}}$ & $34.6^{c}$ & $0.55^{\mathrm{b}}$ & $98.9^{\mathrm{ab}}$ \\
\hline SEM & 0.3152 & 0.5034 & 0.5825 & 0.1665 & 0.5200 & 0.0271 & 4.468 \\
\hline$P$ value & $<0.0001$ & $<0.0001$ & $<0.0001$ & $<0.0001$ & $<0.0001$ & $<0.0001$ & $<0.0001$ \\
\hline
\end{tabular}

${ }^{*}$ Values are expressed as means \pm SEM.

a,b,c,d,e,f Different superscripts indicate significant differences between oils (one-way ANOVA followed by Tuckey test, $P<0.05$ ).

$\Sigma \mathrm{SFA}=$ sum of myristic, palmitic, margaric, stearic, arachidic, behenic and lignoceric acids; $\Sigma \mathrm{MUFA}=$ sum of palmitoleic, oleic and gadoleic acids; $\Sigma$ PUFA = sum of linoleic and linolenic; $\Sigma$ PUFA n-3 = linolenic acid; $\Sigma$ PUFA n- $6=$ linoleic acid.

$75.4 \%$ (olive oil), that is, obviously, the most representative oil of this group. The MUFA content of olive oil does not differ from that of almond oil, which, in turn, is equal to avocado oil, being these three oils significantly higher from all the other oils of the present study. Almond oil may be included in the MUFA group, although it does not appear in previous studies of edible vegetable oils according to their
FA profile $[12,22]$. Our results regarding virgin olive oil were similar to data from literature [23] and are in accordance with specifications of trade standards for olive oils defined by the International Olive Oil Council [14]. Olive oil FA composition has been considered as a parameter to characterize the different olive cultivars [24]. Within the MUFA group, argan oil was classified as MUFA + SFA + linoleic subclass, since 
TABLE 5: Eigenvalues and standardized coefficients of the discriminant functions from the discriminant analysis ${ }^{\mathrm{a}}$.

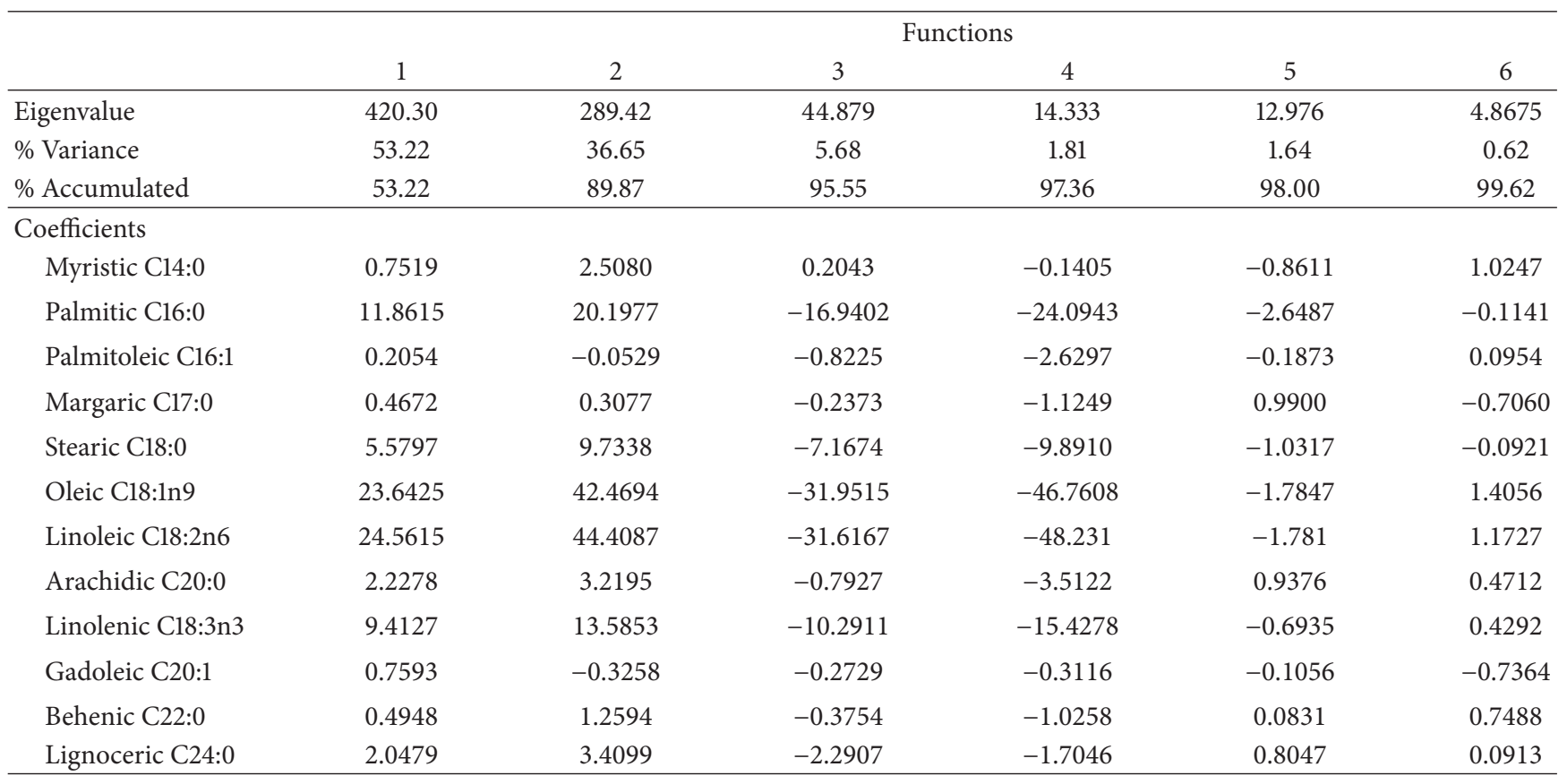

${ }^{\mathrm{a}}$ The first six discriminant functions are shown.

average SFA and linoleic acid contents were higher than in the MUFA group/MUFA subclass, although differences do not reach statistical significance in all cases.

The remaining oils analyzed in the present study, grape seed, wheat germ, sunflower, linseed, walnut, sesame, soybean, and pumpkin oils, were oils from the PUFA group, according to Dubois et al. [12]. The PUFA content in this group ranged from $38 \%$ in sunflower to $70 \%$ in grape seed and linseed oils, with significant differences between the different oils. Grape seed oil belongs to a linoleic acid subclass, as it has $69.3 \%$ content of this FA, significantly higher than all the other oils of the present study and similar to previous reported data $[12,22]$. Walnut oil was classified in the linoleic + SFA subclass and the highest ratio n-6/n-3 was found in this oil compared with all the other analyzed oils. Wheat germ, sunflower, sesame, soybean, and pumpkin oils were classified in the linoleic + MUFA subclass, since these oils, in addition to contain important proportions of linoleic acid, also have high amounts of MUFA, ranging from $16.2 \%$ (wheat germ) to $53.2 \%$ (sunflower). Sunflower oil analyzed in the present assay had much higher oleic acid and lower linoleic acid contents than conventional sunflower oils [13], but it was similar to other sunflower oils currently commercialized in the Spanish market [23]. Sesame oil, like argan oil, had oleic and linoleic acids as major FA, without significant differences of these two FA between both oils. Soybean and pumpkin oils have very similar amounts of MUFA, but soybean showed higher PUFA, due to its special content of linolenic acid (8\% of total FA, significantly different from all the other oils of our study). Finally, the linseed oil is the only one included in the linolenic + MUFA subclass, with an exceptional content of $55.2 \%$ of linolenic acid and thus the lowest ratio n-6/n-3 (0.27) of the total of oils is analyzed. This FA is the precursor of long-chain derivatives like EPA and DHA, and special effects of linseed oils on cardiovascular disease have been widely studied [24].

3.3. Results of the Discriminant Analysis. With the aim of studying the relationships among the oils under a statistical point of view, a multivariate discriminate analysis was applied. As mentioned, this analysis considers information of all the variables, which provide important information and may have effects on the relationships of oils. Moreover, the analysis establishes discriminating functions which can help predicting the type of oil by the values of all the FA represented in the independent variables.

Table 5 displays the eigenvalues obtained in the present analysis. An eigenvalue in discriminant analysis is the characteristic root of each function; that is, it is an indication of how well that function differentiates the groups, and the larger the eigenvalue is, the better the function differentiates the groups. As it is depicted in Table 5, with the three first functions, the $95.55 \%$ of the variance is explained. Table 5 also shows the standardized coefficients of the six first discriminating functions based on the values of the twelve FA analyzed, as discriminant variables. The relative magnitude of the different coefficients allows determining how the different variables affect the discrimination of the oils. Each function is defined by different coefficients, but it may be observed that the most important variables are linoleic and oleic acids, followed by palmitic, linolenic, and stearic acids.

The results of the discriminating analysis can be represented in charts that consist of the possibility to graphically represent the similarity of the type of oil on the basis of two or three dimensions (the discriminating functions). Graphical representation for three dimensions is depicted in Figure 2, 


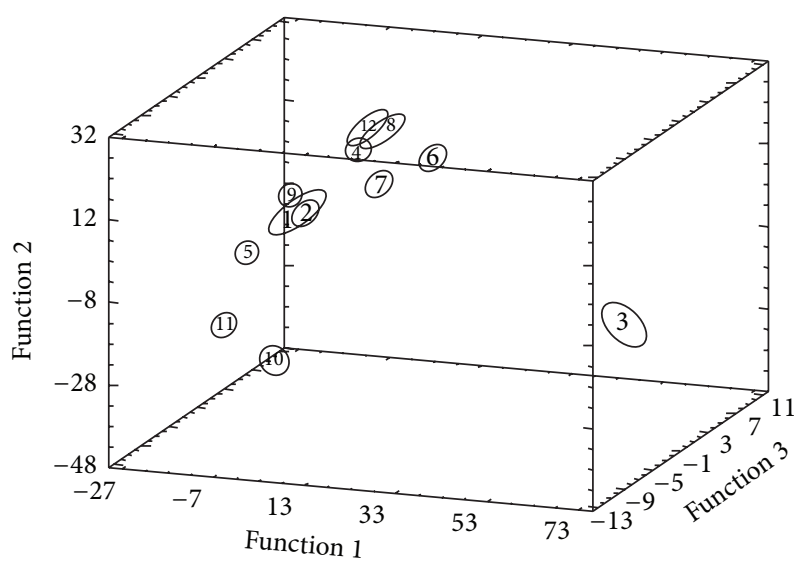

Oils

1 Argan

2 Sesame

3 Linseed

4 Walnut

5 Almond

6 Wheat germ

$\begin{array}{ll}7 & \text { Soybean } \\ 8 & \text { Grape seed } \\ 9 & \text { Sunflower high oleic } \\ 10 & \text { Avocado } \\ 11 & \text { Olive } \\ 12 & \text { Pumpkin }\end{array}$

FIGURE 2: Similarity of the oils based on the first three discriminating functions of the discriminant analysis.

in accordance with the first three discriminating functions. To avoid overlapping derived from marking all the values, we have used an average value of the discriminant function for each one of the oils, that is, the centroid, which has been represented with different numbers. Similarity of objects in a multidimensional scaling is determined on the basis of the measure of distance, and this measure corresponded to the type of data. It must be taken into account that, even when two oils exhibit similarity in the content of a major FA, small differences in the percentage of a minor FA can completely change the characteristics of the oil [25]. From Figure 2 we can see that oils included in the MUFA group (argan, almond, avocado, and olive oils) are relatively close, where avocado and olive oils are the most similar oils. However, from the visual exploration it may be concluded that argan oil has closest relationships with two oils from the PUFA group: sesame and high oleic sunflower, particularly with sesame oil. There is also a close relationship between walnut, grape seed, and pumpkin oils, whereas linseed differs considerably from the other oils. In order to validate the classification method, it was applied to all the samples in accordance with their FA profile, and the predicted group (kind of oil) was correct in $100 \%$ of cases. This proves that this analysis predicts well the corresponding oil observed by means of the chosen predictor variables. The usefulness of the analysis has been previously ascertained by other authors to discriminate the geographical origin of olive oils by their fatty acid composition [26].

\section{Conclusions}

The fatty acid composition of edible oils is a very important aspect in marketing and human health. Virgin argan oil raises nowadays significant scientific and commercial interests outside the Maghreb area, where it is consumed for centuries. In this study, similarities and differences between argan oil and other edible vegetable oils based on their fatty acid profile were established by the application of multivariate discriminant analysis. This method was proven to be a useful tool to study the relationships between oils according to the fat composition; moreover, the importance of the FA variables for the oils classification may be determined and similarities among oils may be easily visualized by graphical representation.

\section{Conflict of Interests}

The authors declare that there is no conflict of interests regarding the publication of this paper.

\section{Acknowledgments}

This work was supported by the research group AGR141 of Junta de Andalucía and a Project of Plan Propio de Investigación de la Universidad de Granada. The assays described are part of the doctoral thesis of Ascension Rueda, from the Official Doctoral Program "Nutrition and Food Sciences" of the Granada University.

\section{References}

[1] H. E. Monfalouti, D. Guillaume, C. Denhez, and Z. Charrouf, "Therapeutic potential of argan oil: a review," Journal of Pharmacy and Pharmacology, vol. 62, no. 12, pp. 1669-1675, 2010.

[2] C. Cabrera-Vique, R. Marfil, R. Giménez, and O. MartínezAugustin, "Bioactive compounds and nutritional significance of virgin argan oil-an edible oil with potential as a functional food," Nutrition Reviews, vol. 70, no. 5, pp. 266-279, 2012.

[3] Z. Charrouf and D. Guillaume, "Should the amazigh diet (regular and moderate argan-oil consumption) have a beneficial impact on human health?" Critical Reviews in Food Science and Nutrition, vol. 50, no. 5, pp. 473-477, 2010.

[4] Norme Marocaine 08.5.090, Huiles d'Argane. Specifications, Ministre de l'Industrie, de l'Energie et des Mines, Rabat, Morocco, 2003.

[5] M. Cherki, H. Berrougui, A. Drissi, A. Adlouni, and A. Khalil, "Argan oil: which benefits on cardiovascular diseases?" Pharmacological Research, vol. 54, no. 1, pp. 1-5, 2006.

[6] S. Sour, M. Belarbi, D. Khaldi et al., "Argan oil improves surrogate markers of CVD in humans," British Journal of Nutrition, vol. 107, no. 12, pp. 1800-1805, 2012.

[7] F. Khallouki, C. Younos, R. Soulimani et al., "Consumption of argan oil (Morocco) with its unique profile of fatty acids, tocopherols, squalene, sterols and phenolic compounds should confer valuable cancer chemopreventive effects," European Journal of Cancer Prevention, vol. 12, no. 1, pp. 67-75, 2003.

[8] M. Hilali, Z. Charrouf, A. E. A. Soulhi, L. Hachimi, and D. Guillaume, "Influence of origin and extraction method on argan oil physico-chemical characteristics and composition," Journal of Agricultural and Food Chemistry, vol. 53, no. 6, pp. 2081-2087, 2005.

[9] R. Marfil, C. Cabrera-Vique, R. Giménez, P. R. Bouzas, O. Martínez, and J. A. Sánchez, "Metal content and physicochemical parameters used as quality criteria in virgin argan oil: 
Influence of the extraction method," Journal of Agricultural and Food Chemistry, vol. 56, no. 16, pp. 7279-7284, 2008.

[10] C. Venegas, C. Cabrera-Vique, L. García-Corzo, G. Escames, D. Acuña-Castroviejo, and L. C. López, "Determination of coenzyme Q 10, coenzyme Q 9, and melatonin contents in virgin argan oils: comparison with other edible vegetable oils," Journal of Agricultural and Food Chemistry, vol. 59, no. 22, pp. 1210212108, 2011.

[11] J. Aranceta, C. Pérez, and J. Mataix, "Ingestas dietéticas de referencia, objetivos nutricionales y guías alimentarias," in Libro Blanco de los Omega 3, C. Pérez, A. Gil, and L. Serra, Eds., pp. 83-103, Editorial Médica Panamericana, Madrid, Spain, 2013.

[12] V. Dubois, S. Breton, M. Linder, J. Fanni, and M. Parmentier, "Fatty acid profiles of 80 vegetable oils with regard to their nutritional potential," European Journal of Lipid Science and Technology, vol. 109, no. 7, pp. 710-732, 2007.

[13] F. F. Ai, J. Bin, Z. M. Zhang et al., "Application of random forests to select premium quality vegetable oils by their fatty acid composition," Food Chemistry, vol. 144, pp. 472-478, 2014.

[14] International Oil Council, "Applicable trade regulations to olive oil and olive residue oil," No. 3/Rev 2, 2006.

[15] A. Cert, W. Moreda, and M. C. Pérez-Camino, "Methods of preparation of fatty acid methyl esters (FAME). Statistical assessment of the precision characteristics from a collaborative trial," Grasas y Aceites, vol. 51, no. 6, pp. 447-456, 2000.

[16] Z. Charrouf, D. Guillaume, and A. Driouich, "The Argan tree, an asset for Morocco," Biofutur, vol. 220, pp. 54-56, 2002.

[17] Z. Charrouf and D. Guillaume, "Argan oil: occurrence, composition and impact on human health," European Journal of Lipid Science and Technology, vol. 110, no. 7, pp. 632-636, 2008.

[18] R. Marfil, C. Cabrera, and R. Gimenez, Importancia Nutricional, Económica y Natural del Aceite de Argán (Argania spinosa), Fundación Euroárabe de Altos Estudios, Madrid, Spain, 2009.

[19] S. M. Soel, O. S. Choi, M. H. Bang, J. H. Yoon Park, and W. K. Kim, "Influence of conjugated linoleic acid isomers on the metastasis of colon cancer cells in vitro and in vivo," Journal of Nutritional Biochemistry, vol. 18, no. 10, pp. 650-657, 2007.

[20] M. Rahmani, "Composition chimique de l'huile d'argane vierge," Cahiers Agricultures, vol. 14, pp. 461-465, 2005.

[21] H. Harhar, S. Gharby, B. Kartah, H. El Monfalouti, D. Guillaume, and Z. Charrouf, "Influence of argan kermel roastingtime on virgin argan oil composition and oxidative stability," Plant Foods for Human Nutrition, vol. 66, no. 2, pp. 163-168, 2011.

[22] N. Vingering, M. Oseredczuk, L. Du Chaffaut, J. Ireland, and M. Ledoux, "Fatty acid composition of commercial vegetable oils from the French market analysed using a long highly polar column," Oleagineux Corps Gras Lipides, vol. 17, no. 3, pp. 185192, 2010.

[23] H. López, M. D. Ruiz, and C. Cabrera-Vique, "Composición y calidad nutritiva de los alimentos," in Tratado de Nutrición, A. Gil and M. D. Ruiz, Eds., pp. 249-279, Editorial Médica Panamericana, Madrid, Spain, 2010.

[24] J. A. Tur, M. M. Bibiloni, A. Sureda, and A. Pons, "Dietary sources of omega 3 fatty acids: public health risks and benefits," British Journal of Nutrition, vol. 107, no. 2, pp. 23-52, 2012.

[25] T. Řezanka and H. Řezanková, "Characterization of fatty acids and triacylglycerols in vegetable oils by gas chromatography and statistical analysis," Analytica Chimica Acta, vol. 398, no. 2-3, pp. 253-261, 1999.
[26] J. J. Sánchez Casas, E. O. Bueno, A. M. M. García, and M. M. Cano, "Study of fatty acid contents in monovariety oils elaborated from olives produced in Extremadura (Spain)," Grasas y Aceites, vol. 54, no. 4, pp. 371-377, 2003. 

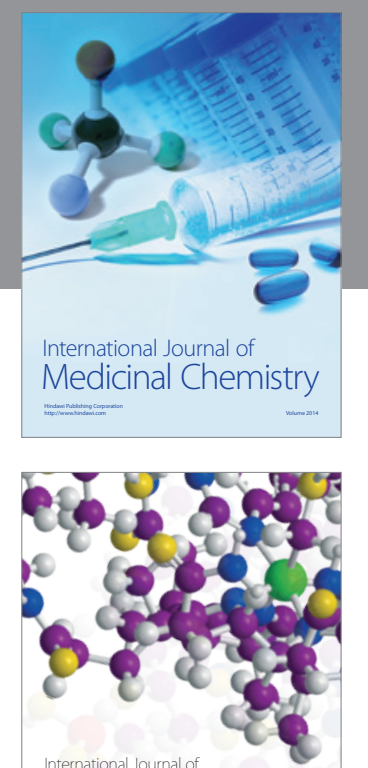

\section{Carbohydrate} Chemistry

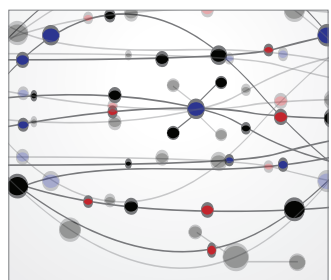

The Scientific World Journal
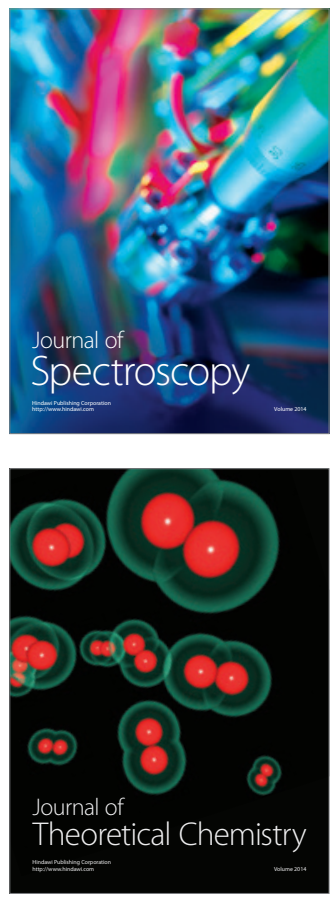
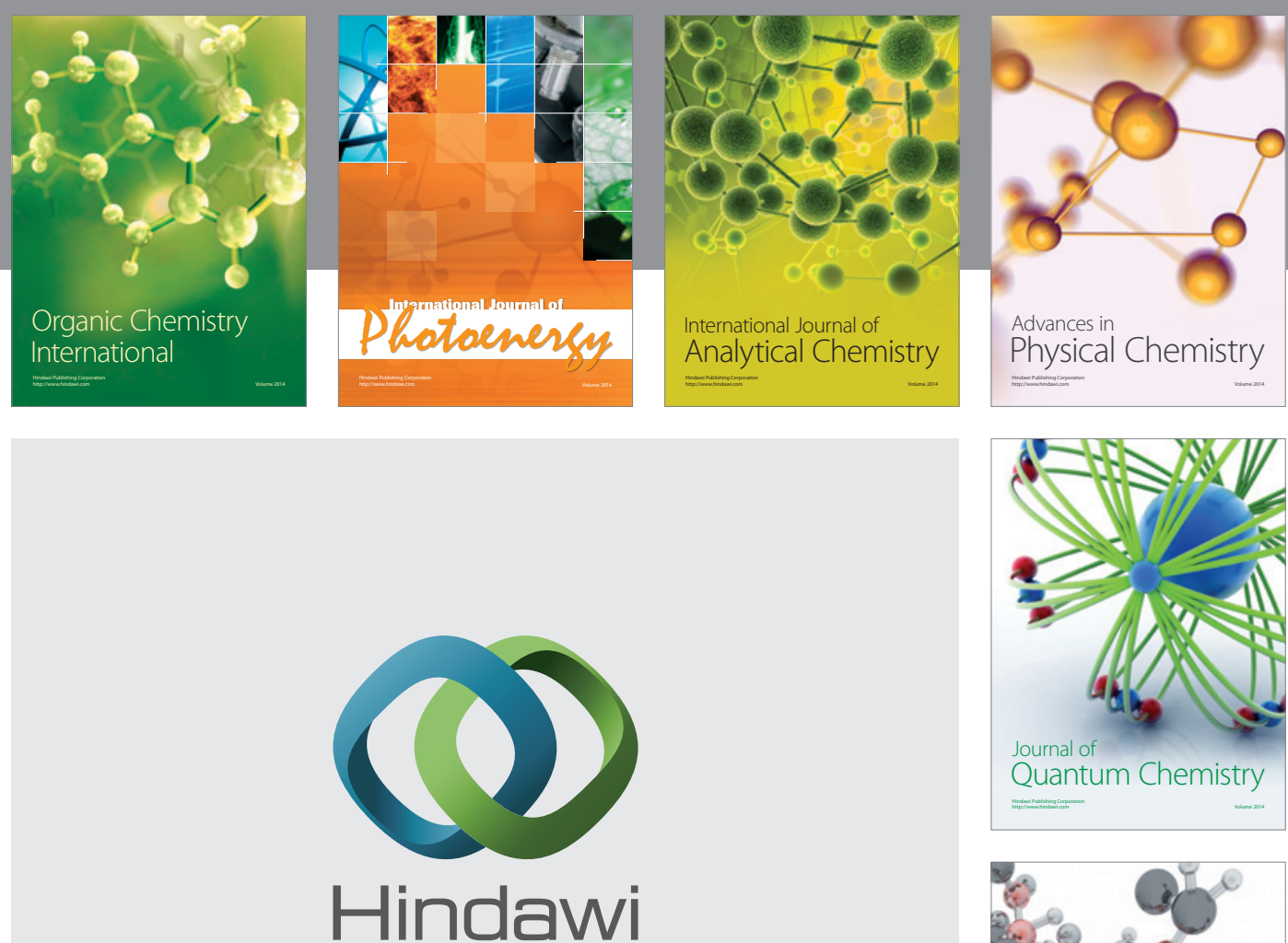

Submit your manuscripts at

http://www.hindawi.com

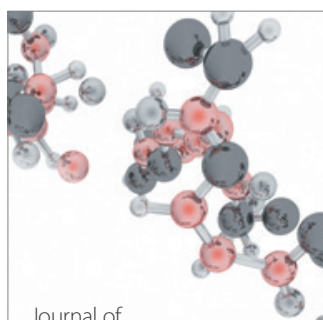

Analytical Methods

in Chemistry

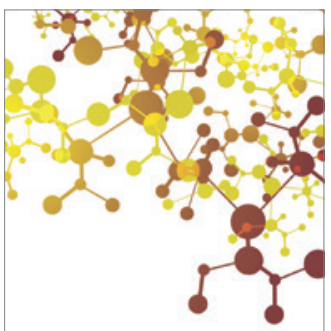

Journal of

Applied Chemistry

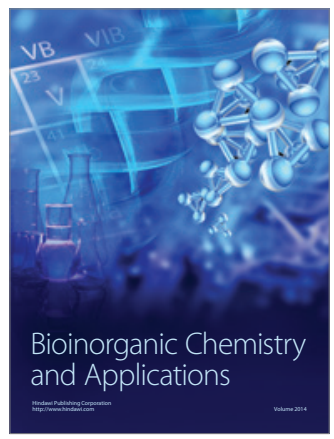

Inorganic Chemistry
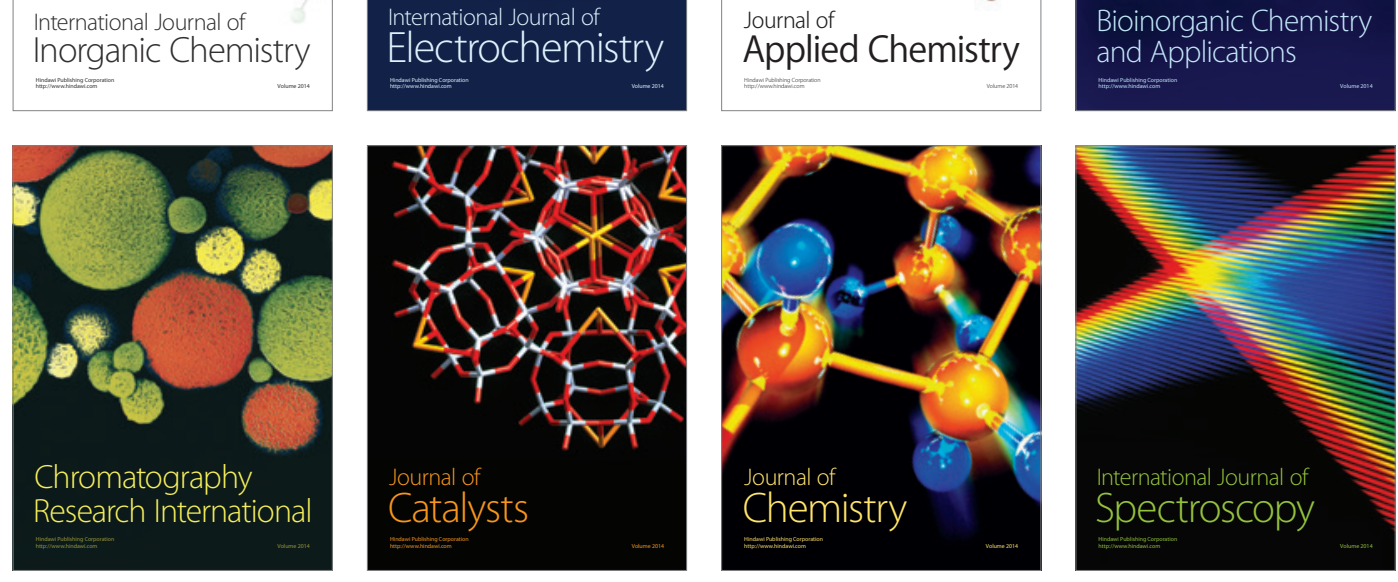